\title{
Extracellular resistance is sensitive to tissue sodium status; implications for bioimpedance-derived fluid volume parameters in chronic kidney disease
}

\author{
Nicos Mitsides ${ }^{1,2,3}$ D $\cdot$ Damien McHugh ${ }^{4} \cdot$ Agnieszka Swiecicka $^{5} \cdot$ Roshni Mitra $^{6} \cdot$ Paul Brenchley $^{1,7}$. \\ Geoff J. M. Parker ${ }^{4,8} \cdot$ Sandip Mitra ${ }^{1,3,7}$
}

Received: 1 March 2019 / Accepted: 6 June 2019 / Published online: 18 June 2019

(c) The Author(s) 2019

\begin{abstract}
Multifrequency bioimpedance spectroscopy (BIS) is an established method for assessing fluid status in chronic kidney disease (CKD). However, the technique is lacking in predictive value and accuracy. BIS algorithms assume constant tissue resistivity, which may vary with changing tissue ionic sodium concentration $\left(\mathrm{Na}^{+}\right)$. This may introduce significant inaccuracies to BIS outputs. To investigate this, we used ${ }^{23} \mathrm{Na}$ magnetic resonance imaging (MRI) to measure $\mathrm{Na}^{+}$in muscle and subcutaneous tissues of 10 healthy controls (HC) and 20 patients with CKD 5 (not on dialysis). The extracellular (Re) and intracellular (Ri) resistance, tissue capacitance, extracellular (ECW) and total body water (TBW) were measured using BIS. Tissue water content was assessed using proton density-weighted MRI with fat suppression. BIS-derived volume indices were compara-

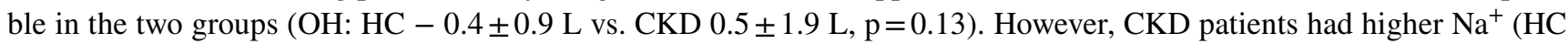
$21.2 \pm 3.0, \mathrm{CKD} 25.3 \pm 7.4 \mathrm{mmol} / \mathrm{L} ; \mathrm{p}=0.04)$ and significantly lower Re (HC $693 \pm 93.6, \mathrm{CKD} 609 \pm 74.3 \mathrm{Ohms} ; \mathrm{p}=0.01)$; $\mathrm{Ri}$ and capacitance did not vary. $\mathrm{Na}^{+}$showed a significant inverse linear relationship to $\operatorname{Re}\left(\mathrm{r}_{\mathrm{s}}=-0.598, \mathrm{p}<0.01\right)$ but not $\mathrm{Ri}$. This relationship of $\operatorname{Re}(\mathrm{y})$ and $\mathrm{Na}^{+}(\mathrm{x})$ is described through equation $\mathrm{y}=-7.39 \mathrm{x}+814$. A $20 \%$ increase in tissue ionic $\mathrm{Na}^{+}$is likely to overestimate ECW by 1.2-2.4L. Tissue $\mathrm{Na}^{+}$concentration has a significant inverse linear relationship to Re. BIS algorithms to account for this effect could improve prediction accuracy of bioimpedance derived fluid status in CKD.
\end{abstract}

Keywords Bioimpedance $\cdot$ Sodium $\cdot$ CKD

Electronic supplementary material The online version of this article (https://doi.org/10.1007/s40620-019-00620-3) contains supplementary material, which is available to authorized users.

Nicos Mitsides

nicos.mitsides3@srft.nhs.uk

1 Division of Cardiovascular Sciences, School of Medical Sciences, Faculty of Biology, Medicine and Health, The University of Manchester, Manchester Academic Health Science Centre, Manchester, UK

2 Nephrology Department, Salford Royal Hospital NHS Foundation Trust, Stott Lane, Salford M6 8HD, UK

3 NIHR Devices for Dignity Medical Technology Co-operative, Sheffield, UK

4 Quantitative Biomedical Imaging Laboratory, Faculty of Biology, Medicine and Health, University of Manchester,

\section{Introduction}

Extracellular volume (ECW) expansion is commonly encountered in advanced chronic kidney disease (CKD) [1]. Salt and water retention leading to fluid overload (FO) through loss of renal function presents a significant

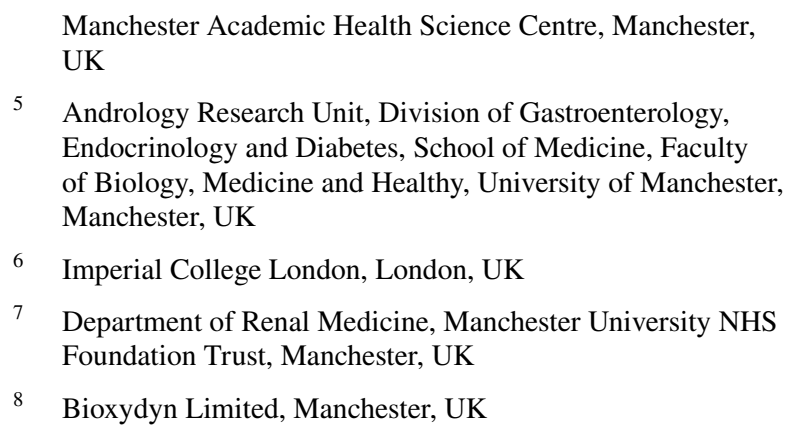
UK

5 Andrology Research Unit, Division of Gastroenterology, Endocrinology and Diabetes, School of Medicine, Faculty of Biology, Medicine and Healthy, University of Manchester, Manchester, UK

6 Imperial College London, London, UK

7 Department of Renal Medicine, Manchester University NHS Foundation Trust, Manchester, UK

8 Bioxydyn Limited, Manchester, UK 
cardiovascular risk factor and a major clinical challenge, especially in dialysis-dependant CKD with anuria [2-4]. The assessment of FO in CKD through the use of electrical bioimpedance spectroscopy (BIS) has been introduced into clinical practice for more accurate prediction of fluid balance with a potential impact on outcomes [5-7].

BIS utilises the principle that body tissue compartments have different resistance and reactance to different frequencies of alternating electrical current (AC). Low frequencies $(\leq 5 \mathrm{kHz})$ can only transverse the $\mathrm{ECW}$ while high frequencies $(>100-200 \mathrm{kHz}$ ) propagate through both ECW and intracellular water (ICW) compartments. The work of Thomasset $[8,9]$ enabled the measurement of the water volume of a compartment with a known length and electrical resistance using the equation [9]:

$\mathrm{V}=\rho \frac{L^{2}}{Z}$

where $\mathrm{V}=$ total body water [TBW $(\mathrm{ml})], \rho=$ tissue resistivity $(\mathrm{Ohm} \mathrm{cm}), \mathrm{L}=$ conductor length $(\mathrm{cm}), \mathrm{Z}=$ impedance (Ohm).

To measure TBW, BIS assumes that $\rho$ remains constant and the human body behaves as a cylinder with isotropic conductivity [10]. Whole body multifrequency BIS uses multiple frequencies of $\mathrm{AC}(5-1000 \mathrm{kHz})$ to measure impedance and phase angle $(\Phi)$ at all these frequencies. Impedance is a derivative of tissue resistance and reactance and represents its insulating and conductive ratio [11]. The resistance of a tissue to an electric current is inversely related to its water content while its reactance relates to its cell mass [11], if the assumptions hold true. The relationship between the resistance and reactance is characterised by $\Phi$. This represents the cumulative time delay that occurs when AC transverses through cell membranes [11]. The more cellular the tissue, the higher the $\Phi$. Tissue cellularity and cellular health is also reflected by tissue capacitance (the ability to store electricity for a short period of time). From these measurements the BIS device will derive the extracellular ( $\mathrm{Re})$ and intracellular (Ri) resistance and through the use of the Cole-Cole [10] model, and either the Xitron [12] or Moissl [13] equations, estimate ECW and TBW.

The $\rho$ of body fluid compartments is influenced by ions such as sodium $\left(\mathrm{Na}^{+}\right)$, potassium and chloride, and their relative extra- and intracellular distribution [14]. It has been observed that post-dialysis BIS measurements of ICW can markedly vary from pre-dialysis measurements; this has been attributed to electrolyte changes [15]. A key assumption by BIS algorithms is that the ionic tissue composition remains stable in relation to water. However, the variation in tissue electrolyte concentrations and its impact on BIS measurements has not been studied in human subjects.

$\mathrm{Na}^{+}$as the dominant ion in the body is the predominant contributor to tissue $\rho$. It has been assumed that due to its close affinity to water, high levels of $\mathrm{Na}^{+}$are mirrored by water volume expansion $[16,17]$. It has been suggested that $\mathrm{Na}^{+}$could exist in a water-free form, predominantly attached to the proteoglycan matrix of tissues such as the skin [18, 19]. The use of ${ }^{23} \mathrm{Na}$ magnetic resonance imaging (MRI) provides a reproducible, non-invasive method for measuring tissue $\mathrm{Na}^{+}[20]$. Studies using this technique have reported high $\mathrm{Na}^{+}$in patients with CKD [21].

In haemodialysis patients BIS has been used to guide fluid ultrafiltration and help adjust the target weight. The highly reproducible nature of BIS (intra- and inter-observer error $<2 \%$ ) makes this method useful for monitoring fluid status changes in individuals [22]. However, despite a good overall correlation between BIS and isotopic measurements of TBW and ECW [9], the window of error for ECW estimates can be up to $17 \%$ [13]. This translates to an intrinsic methodological variation of $\pm 2.8 \mathrm{~L}$ [13] limiting its use in clinical practice. Deviations from euvolaemia within this range have been associated with higher all-cause and cardiovascular mortality in dialysis [7]. Accuracy in ECW prediction therefore may be crucial in improving clinical outcomes in CKD.

We hypothesised that varying tissue $\mathrm{Na}^{+}$concentration can influence impedance measured through BIS and we aimed to assess its impact on BIS predictive accuracy.

\section{Methods}

This is a cross-sectional case-control study examining the association between measurements of $\mathrm{Na}^{+}$tissue concentration derived by ${ }^{23} \mathrm{Na} \mathrm{MRI}$ and fluid volume measurements from multifrequency BIS in patients with advanced CKD and healthy subjects (HC). In a subgroup of participants, fluid in the lower limb was also assessed using conventional proton MRI. The study received approval by the North West NHS Research Ethics Committee (15/NW/0471). All adult patients with eGFR $<15 \mathrm{ml} / \mathrm{min}$ (pre-dialysis) and ability to consent, receiving their care at the participating centre were able to participate in the study. $\mathrm{HC}$ were recruited through posters placed at the participating centre. All adults with no history of CKD were eligible. The only exclusion criteria for both groups were contraindication to MRI and limb amputation. Written informed consent was obtained prior to enrolment into the study. All study measurements and blood tests were performed during a single visit by one operator, in a controlled hospital environment. Medical and drug histories were obtained from the participants and their 
Fig. $1{ }^{23}$ Sodium magnetic resonance image of the left lower limb of a patient with advanced chronic kidney disease (4a). Underneath the calf muscle the five saline phantoms can be seen. ${ }^{1} \mathrm{H}$ magnetic resonance image of the left lower limb of a patient with advanced chronic kidney disease acquired using a proton density-weighted scan with SPAIR fat suppression (4b)
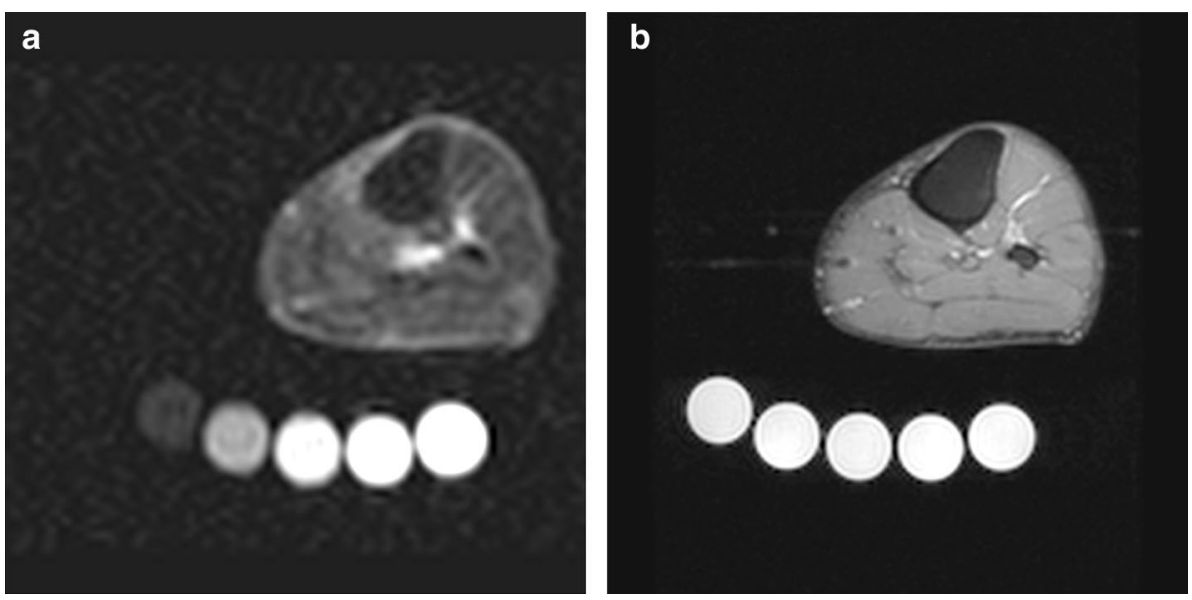

electronic medical records. Participants' blood samples were analysed for serum electrolytes, urea and creatinine, albumin and osmolality at the participating centre's NHS laboratory. The laboratory also reported the MDRD eGFR.

\section{Fluid assessment using BIS}

Whole body multifrequency BIS was performed using the Body Composition Monitor $\left(\mathrm{BCM}^{\circledR}\right.$, Fresenius Medical Care, Germany) as per manufacturer's specifications. The device provided measurements of $\mathrm{Re}, \mathrm{Ri}$ and tissue capacitance, as well as impedance and $\Phi$ for individual frequencies $(5-1000 \mathrm{kHz})$. The software, based on impedance, calculated TBW, ECW and ICW.

\section{MRI}

Imaging was performed using a 3T MRI scanner (Philips 3T Achieva). Images were acquired using a dual-tuned ${ }^{1} \mathrm{H} /{ }^{23} \mathrm{Na}$ head coil (RAPID Biomedical GmbH, Germany). Analysis was performed using Horos Image Viewer Version 1.7 (www.horosproject.org).

\section{Sodium imaging}

An adapted version of the protocol used by Kopp et al. [23] was used for acquiring ${ }^{23} \mathrm{Na}$ images between the levels of the left knee and ankle. All images (Fig. 1a) were analysed by two operators and the reported $\mathrm{Na}^{+}$for muscle $\left(\mathrm{Na}_{\mathrm{M}}^{+}\right)$ and subcutaneous $\left(\mathrm{Na}_{\mathrm{SC}}^{+}\right)$tissue was the average of the two measurements (Supplementary Tables 1 and 2). The average of the $\mathrm{Na}^{+}$concentration of these two tissue compartments was then reported as $\mathrm{Na}_{\mathrm{AveSC}+\mathrm{M}}^{+}$concentration. A detailed method for deriving $\mathrm{Na}^{+}$concentration is presented in Supplementary Material 1 . The average method coefficient of variation for signal intensity calibration was $13.9 \%$. The mean inter-reader variation for $\mathrm{Na}_{\mathrm{M}}^{+}$was $0.07 \pm 3.5 \mathrm{mmol} / \mathrm{L}$ and $\mathrm{Na}_{\mathrm{SC}}^{+}$was $-1.21 \pm 3.9 \mathrm{mmol} / \mathrm{L}$.

\section{MRI tissue water measurement}

To analyse tissue water content in the muscle and subcutaneous (SC) tissue, we used an adaptation of the approach used by Dahlmann et al. [21]. ${ }^{1} \mathrm{H}$ images were acquired using a proton density-weighted scan with SPAIR fat suppression (Fig. 1b). All images were reported by two operators and the reported muscle and SC tissue fractional water content (FWC) was the average of the two readers. A detailed method for image acquisition and deriving FWC is presented in Supplementary Material 1 . The average technique coefficient of variation of signal intensity with the phantom was $2.5 \%$. The mean inter-reader variation of FWC for muscle was $0.019 \pm 0.05$ and for SC was $-0.027 \pm 0.05$ (Supplementary Tables 3, 4).

\section{Statistics}

Cohort characteristics and measurements were explored using descriptive epidemiology. Categorical variables were reported as percentages and ratios. Continuous variables were reported as mean (standard deviation) where distribution was normal and as median (minimum and maximum) when distribution was skewed. Normality of distribution was assessed using the Shapiro-Wilk method. Comparison of categorical variables between the study groups was performed using Pearson's Chi ${ }^{2}$. Group comparison of continuous variables was performed using paired $t$ test and Mann-Whitney test based on the distribution.

Associations between BIS measurements, body composition estimations and $\mathrm{Na}^{+}$and water MRI measurements were explored using Pearson's correlation for normally distributed variables and Spearman's correlation when variables' distribution was skewed. Statistical analysis was performed using IBM SPSS Statistics, version 23 (IBM Corp., USA). 
Table 1 Participants' bioimpedance and MR measurements

\begin{tabular}{|c|c|c|c|c|}
\hline & Entire cohort & Controls & Advanced CKD & $\mathrm{p}$ value \\
\hline \multicolumn{5}{|c|}{ Bioimpedance measurements } \\
\hline $\operatorname{Re}(\mathrm{Ohms})$ & 637.0 (SD 89.2) & 693.2 (SD 93.6) & $608.9($ SD 74.3) & $0.012 *$ \\
\hline $\mathrm{Ri}(\mathrm{Ohms})$ & $1571.2(\mathrm{SD} 303.3)$ & $1626.9(\mathrm{SD} 338.5)$ & $1543.3(\mathrm{SD} 289.3)$ & 0.486 \\
\hline Capacitance (nF) & $1.4(0.7-3.4)$ & $1.4(1.1-3.4)$ & $1.4(0.7-3.2)$ & 0.895 \\
\hline \multicolumn{5}{|l|}{$\mathrm{Z}(\mathrm{Ohms})$} \\
\hline $5 \mathrm{kHz}$ & 611.9 (SD 87.0) & 664.4 (SD 96.4) & 585.7 (SD 70.5) & $0.017 *$ \\
\hline $100 \mathrm{kHz}$ & $518.3($ SD 71.1) & 558.0 (SD 82.6) & 498.5 (SD 56.9) & $0.028 *$ \\
\hline \multicolumn{5}{|l|}{$\Phi\left({ }^{\circ}\right)$} \\
\hline $5 \mathrm{kHz}$ & $2.5(1.5-4.4)$ & $2.6(2.2-4.4)$ & $2.5(1.5-4.1)$ & 0.311 \\
\hline $100 \mathrm{kHz}$ & $5.0(\mathrm{SD} 0.8)$ & $5.3(\mathrm{SD} 0.5)$ & $4.9(\mathrm{SD} 0.9)$ & 0.225 \\
\hline \multicolumn{5}{|c|}{ Body composition estimations } \\
\hline TBW/Weight $(\mathrm{L} / \mathrm{kg})$ & $0.46(\mathrm{SD} 0.08)$ & $0.47(\mathrm{SD} 0.08)$ & $0.46(\mathrm{SD} 0.08)$ & 0.681 \\
\hline ECW & $16.3(\mathrm{SD} 2.84)$ & $15.5(\mathrm{SD} 3.30)$ & $16.6(\mathrm{SD} 3.29)$ & 0.314 \\
\hline $\mathrm{OH}(\mathrm{L})$ & $0.2(\mathrm{SD} 1.3)$ & $-0.4(\mathrm{SD} 0.9)$ & $0.5(\mathrm{SD} 1.5)$ & 0.087 \\
\hline $\mathrm{BMI}\left(\mathrm{kg} / \mathrm{m}^{2}\right)$ & $27.5(\mathrm{SD} 4.6)$ & $25.7(\mathrm{SD} 4.8)$ & $28.4(\mathrm{SD} 4.4)$ & 0.127 \\
\hline \multicolumn{5}{|c|}{ MR-derived Na Conc (mmol/L) } \\
\hline $\mathrm{Na}_{\mathrm{M}}^{+}$ & $24.19(\mathrm{SD} 4.8)$ & $22.77(\mathrm{SD} 2.5)$ & $24.90($ SD 5.5) & 0.257 \\
\hline $\mathrm{Na}_{\mathrm{SC}}^{+}$ & $21.22(12.79-52.38)$ & $18.35(16.09-31.18)$ & $22.43(12.79-52.38)$ & 0.031* \\
\hline $\mathrm{Na}_{\text {AveSC}+\mathrm{M}}^{+}$ & 23.96 (SD 6.5) & 21.21 (SD 3.0) & $25.34($ SD 7.4) & $0.039 *$ \\
\hline \multicolumn{5}{|c|}{ MR-derived water content fraction } \\
\hline Muscle & $0.50(\mathrm{SD} 0.04)(\mathrm{N}=17)$ & $0.49(\mathrm{SD} 0.04)(\mathrm{N}=4)$ & $0.50(\mathrm{SD} 0.05)(\mathrm{N}=13)$ & 0.744 \\
\hline Subcutaneous & $0.24($ SD 0.10) $(\mathrm{N}=17)$ & $0.18($ SD 0.02$)(N=4)$ & $0.26($ SD 0.11) $(\mathrm{N}=13)$ & $0.023 *$ \\
\hline \multicolumn{5}{|l|}{ Serum biochemistry } \\
\hline $\mathrm{Na}^{+}(\mathrm{mmol} / \mathrm{L})$ & $141.0(136-144)$ & $140.5(136-143)$ & $141.5(137-144)$ & 0.609 \\
\hline Potassium (mmol/L) & $4.8(3.7-5.5)$ & $4.5(4.0-5.4)$ & $5.0(3.7-5.5)$ & 0.250 \\
\hline Bicarb (mmol/L) & 21.8 (SD 3.1) & 24.6 (SD 1.7) & 20.5 (SD 2.7) & $<0.001 *$ \\
\hline Urea $(\mathrm{mmol} / \mathrm{L})$ & 16.9 (SD 9.9) & 4.9 (SD 0.9) & 23.0 (SD 5.9) & $<0.001 *$ \\
\hline Creatinine $(\mathrm{mmol} / \mathrm{L})$ & 326.2 (SD 208.8) & 70.2 (SD 10.4) & 454.2 (SD 121.4) & $<0.001 *$ \\
\hline eGFR $\left(\mathrm{ml} / \mathrm{min} / 1.73 \mathrm{~m}^{2}\right)$ & 36.2 (SD 36.5) & 86.5 (SD 7.4) & $11.0($ SD 2.7) & $<0.001 *$ \\
\hline Albumin $(\mathrm{g} / \mathrm{L})$ & $38(29-42)$ & $39(35-42)$ & $37(29-40)$ & 0.051 \\
\hline Osmolality (mOsm/kg) & $301.5(274-338)$ & $290.5(274-298)$ & $307.0(293-338)$ & $<0.001 *$ \\
\hline
\end{tabular}

The bold value is used for correlation co-efficient and p-values with statistical significance

Bicarb bicarbonate, $B M I$ body mass index, $C K D$ chronic kidney disease, Conc concentration, $E C W$ extracellular water, $e G F R$ estimated glomerular filtration rate, $g$ gram, $\mathrm{kg}$ kilogram, $L$ litre, $m$ metre, $\mathrm{min}$ minute, $\mathrm{ml}$ millilitre, $\mathrm{mmol}$ millimole, $\mathrm{mOsm}$ millliosmole, $M R$ magnetic resonance, $\mathrm{Na}^{+}$sodium, $\mathrm{Na}_{\mathrm{AveS}+\mathrm{M}} \stackrel{+}{\mathrm{av}}$ average of muscle and subcutaneous sodium, $\mathrm{Na} \mathrm{M}_{\mathrm{M}}^{+}$muscle sodium, $\mathrm{Na}_{\mathrm{SC}}^{+}$subcutaneous sodium, $\mathrm{nF}$ nanofarad, $\mathrm{OH}$ overhydration index, $R e$ extracellular resistance, $R i$ intracellular resistance, $S D$ standard deviation, $T B W$ total body water, $Z$ impedance, $\Phi$ phase angle

*Indicates significance of $<0.05$

\section{Results}

Thirty subjects (10 HC and 20 advanced CKD) were studied. Both cohorts were of similar age (HC: $51.6 \pm 13.4$ years, CKD: $53.0 \pm 9.3$ years; $p=0.749)$ and sex $(1: 1)$. The CKD group had higher comorbidity, prevalence of hypertension, pill burden and deranged biochemistry in keeping with advanced CKD (eGFR $11 \pm 2.7 \mathrm{ml} / \mathrm{min} / 1.73 \mathrm{~m}^{2}$ ) when compared to HC $\left(86.5 \pm 7.4 \mathrm{ml} / \mathrm{min} / 1.73 \mathrm{~m}^{2}\right.$ ) (Supplementary Table 5). Both cohorts had comparable $\mathrm{OH}(\mathrm{HC}-0.4 \pm 0.9 \mathrm{~L}$ vs. CKD 0.5 $\pm 1.9 \mathrm{~L}$ ) (Table 1, Fig. 2).

\section{Tissue $\mathrm{Na}^{+}$concentration}

CKD participants had significantly higher $\mathrm{Na}_{\text {AveSC}+\mathrm{M}}^{+}$ (HC: $21.2 \pm 3.0 \mathrm{mmol} / \mathrm{L}, \mathrm{CKD}: 25.3 \pm 7.4 \mathrm{mmol} / \mathrm{L}$; $\mathrm{p}=0.039)$ and $\mathrm{Na}_{\mathrm{sc}}^{+}(\mathrm{HC}: 19.7 \pm 4.5 \mathrm{mmol} / \mathrm{L}, \mathrm{CKD}$ : $25.8 \pm 10.3 \mathrm{mmol} / \mathrm{L} ; \mathrm{p}=0.031$ ) (Table 2, Fig. 2). Variations in $\mathrm{Na}_{\mathrm{M}}^{+}$were also observed, but were not significantly different between the cohorts. Measurement data are provided in Supplementary Tables 2, 3. OH correlated significantly with $\mathrm{Na}_{\text {AveSC}+\mathrm{M}}^{+}$(Table 2 ). 
Fig. 2 CKD patients have higher total and subcutaneous MR-derived sodium concentration than healthy controls despite comparable volume indices. $C K D$ chronic kidney disease, $E C W$ extracellular water, $L$ litres, $m m o l$ millimole, $T B W$ total body water. *Indicates statistical significance $(\mathrm{p}<0.05)$
Table 2 Correlation of bioimpedance measurements and bioimpedance-derived body composition to MR-derived tissue sodium concentration for the entire cohort
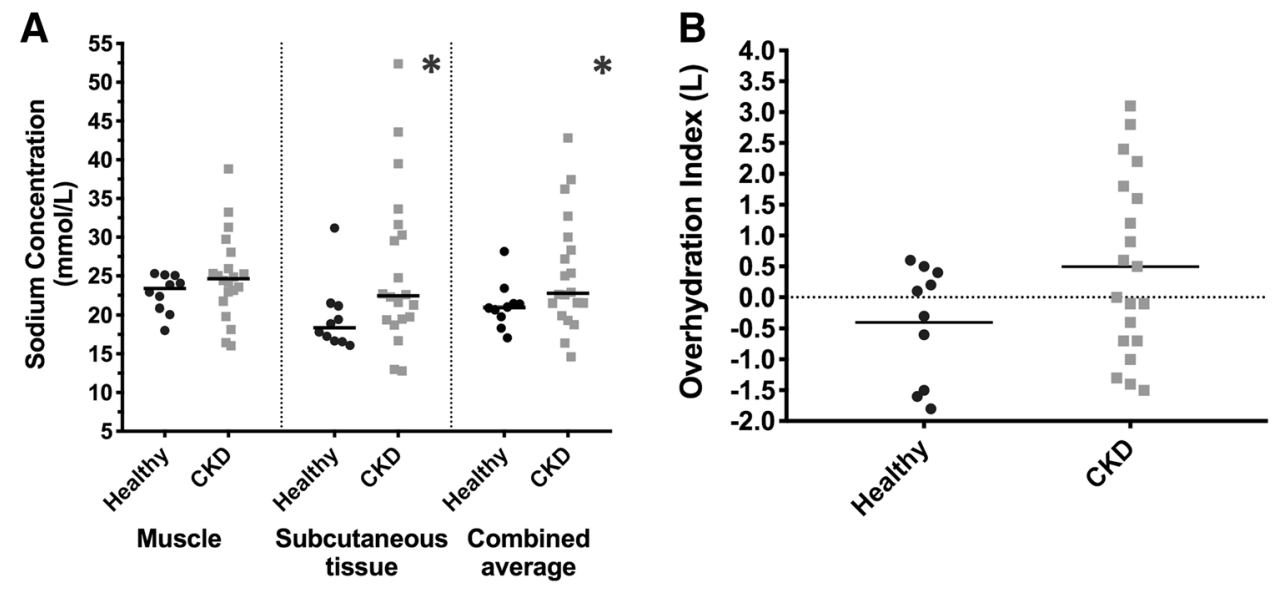

\begin{tabular}{|c|c|c|c|c|c|c|}
\hline & \multicolumn{2}{|l|}{$\mathrm{Na}_{\mathrm{M}}^{+}$} & \multicolumn{2}{|l|}{$\mathrm{Na}_{\mathrm{SC}}^{+}$} & \multicolumn{2}{|c|}{$\mathrm{Na}_{\mathrm{AveSC}+\mathrm{M}}^{+}$} \\
\hline & $\mathrm{r}$ & $\mathrm{p}$ value & $\mathrm{r}$ & $\mathrm{p}$ value & $\mathrm{r}$ & $\mathrm{p}$ value \\
\hline Serum osmolality & 0.222 & 0.239 & 0.488 & $0.006 *$ & 0.382 & $\mathbf{0 . 0 3 7 *}$ \\
\hline \multicolumn{7}{|c|}{ Bioimpedance measurements } \\
\hline $\operatorname{Re}$ & -0.415 & $0.023 *$ & -0.694 & $<0.001 *$ & -0.598 & $<0.001 *$ \\
\hline $\mathrm{Ri}$ & 0.160 & 0.397 & -0.257 & 0.170 & -0.050 & 0.795 \\
\hline Capacitance & -0.402 & $0.028 *$ & 0.010 & 0.956 & -0.206 & 0.276 \\
\hline \multicolumn{7}{|l|}{$\mathrm{Z}$} \\
\hline $5 \mathrm{kHz}$ & -0.423 & $0.020 *$ & -0.712 & $<0.001 *$ & -0.609 & $<0.001 *$ \\
\hline $100 \mathrm{kHz}$ & -0.289 & 0.122 & -0.650 & $<0.001 *$ & -0.499 & $0.005 *$ \\
\hline \multicolumn{7}{|l|}{$\Phi$} \\
\hline $5 \mathrm{kHz}$ & -0.481 & $0.007 *$ & -0.169 & 0.372 & -0.372 & $0.043 *$ \\
\hline $100 \mathrm{kHz}$ & -0.634 & $<0.001 *$ & -0.454 & $0.012 *$ & -0.588 & $0.001 *$ \\
\hline \multicolumn{7}{|c|}{ Body composition estimations } \\
\hline TBW/weight & -0.128 & 0.501 & 0.145 & 0.444 & -0.017 & 0.928 \\
\hline ECW & 0.217 & 0.249 & 0.507 & $0.004 *$ & 0.384 & $0.036 *$ \\
\hline $\mathrm{OH}$ & 0.495 & $0.005^{*}$ & 0.432 & $0.017 *$ & 0.507 & 0.004* \\
\hline
\end{tabular}

The bold value is used for correlation co-efficient and p-values with statistical significance

The relationship between variables was assessed using Spearman's correlation. $E C W$ extracellular water, $\mathrm{Na}_{\text {AveSC+M}} \stackrel{+}{\mathrm{O} C+}$ average of muscle and subcutaneous sodium, $\mathrm{Na} \mathrm{M}_{\mathrm{M}}^{+}$muscle sodium, $\mathrm{Na} \mathrm{a}_{S C}^{+}$subcutaneous sodium, $\mathrm{OH}$ overhydration index, $r$ correlation coefficient, $R e$ extracellular resistance, $R i$ intracellular resistance, $T B W$ total body water, $Z$ impedance, $\Phi$ phase angle

*Indicates significance of $<0.05$

\section{Tissue impedance in CKD}

Impedance at both low $(5 \mathrm{kHz})$ and high $(100 \mathrm{kHz})$ frequencies was significantly lower in the CKD group resulting in higher volume estimates (Table 1). Re was also significantly lower in CKD (HC: $693 \pm 94$ Ohms, CKD: $609 \pm 74$ Ohms; $p=0.012$ ) but Ri, capacitance and $\Phi$ did not vary between the two groups (Table 1).

\section{Tissue $\mathrm{Na}^{+}$, impedance and BIS-derived body composition}

Re exhibited an inverse relationship with tissue $\mathrm{Na}^{+}$concentrations for both muscle and skin compartments $\left(\mathrm{Na}_{\mathrm{M}}^{+}\right.$: $\mathrm{r}=-0.415, \mathrm{p}=0.023 ; \mathrm{Na}_{\mathrm{SC}}^{+}: \mathrm{r}=-0.694, \mathrm{p}<0.001$; $\mathrm{Na}_{\text {AveSC }+\mathrm{M}}^{+}: \mathrm{r}=-0.598, \mathrm{p}<0.001$ ) (Table 2, Fig. 3). The relationship is described by the linear equation

$$
\mathrm{Re}=-7.39 N a_{\mathrm{AveSC}+\mathrm{M}}^{+}+814
$$


Table 3 Correlation of multifrequency bioimpedance measurements, bioimpedance-derived body composition and MR-derived tissue sodium concentration to tissue fractional water content measured by MRI for the entire cohort

\begin{tabular}{|c|c|c|c|c|}
\hline & \multicolumn{2}{|c|}{ Muscle water fraction } & \multicolumn{2}{|c|}{$\begin{array}{l}\text { Subcutaneous water } \\
\text { fraction }\end{array}$} \\
\hline & $\mathrm{r}$ & $\mathrm{p}$ value & $\mathrm{r}$ & $\mathrm{p}$ value \\
\hline \multicolumn{5}{|c|}{ Bioimpedance measurements } \\
\hline $\mathrm{Re}$ & $-0.362^{\wedge}$ & 0.145 & -0.419 & 0.094 \\
\hline $\mathrm{Ri}$ & $-0.475^{\wedge}$ & 0.054 & -0147 & 0.573 \\
\hline Capacitance & -0.223 & 0.390 & -0.287 & 0.264 \\
\hline \multicolumn{5}{|l|}{ Z } \\
\hline $5 \mathrm{kHz}$ & $-0.377^{\wedge}$ & 0.135 & -0.441 & 0.076 \\
\hline $100 \mathrm{kHz}$ & $-0.433^{\wedge}$ & 0.075 & -0.343 & 0.178 \\
\hline \multicolumn{5}{|l|}{$\Phi$} \\
\hline $5 \mathrm{kHz}$ & $0.174^{\wedge}$ & 0.503 & -0.161 & 0.538 \\
\hline $100 \mathrm{kHz}$ & $0.086^{\wedge}$ & 0.742 & -0.424 & 0.090 \\
\hline \multicolumn{5}{|c|}{ Body composition estimations } \\
\hline TBW/weight & $0.418^{\wedge}$ & 0.095 & 0.252 & 0.328 \\
\hline ECW & $0.396^{\wedge}$ & 0.232 & 0.164 & 0.529 \\
\hline $\mathrm{OH}$ & $0.006^{\wedge}$ & 0.980 & 0.258 & 0.318 \\
\hline $\mathrm{Na}_{\mathrm{M}}^{+} \mathrm{Conc}$ & -0.086 & 0.743 & 0.502 & $0.040 *$ \\
\hline $\mathrm{Na}_{\mathrm{SC}}^{+}$Conc & 0.172 & 0.510 & 0.726 & $<0.001$ \\
\hline $\mathrm{Na}_{\text {AveSC}+\mathrm{M}}^{+}$ & 0.044 & 0.866 & 0.681 & $0.003 *$ \\
\hline
\end{tabular}

The bold value is used for correlation co-efficient and $\mathrm{p}$-values with statistical significance

The relationship between variables was assessed using Pearson's correlation for normally distributed variables and Spearman's correlation when distribution was skewed. $E C W$ extracellular water, $\mathrm{kg}$ kilogram,

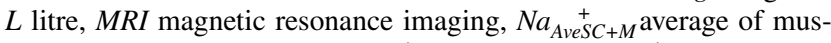
cle and subcutaneous sodium, $\mathrm{Na}_{\mathrm{M}}^{+}$muscle sodium, $\mathrm{Na} \mathrm{SC}_{\mathrm{C}}^{+}$subcutaneous sodium, $\mathrm{OH}$ overhydration index, $r$ correlation coefficient, $R e$ extracellular resistance, $R i$ intracellular resistance, $T B W$ total body water, $Z$ impedance, $\Phi$ phase angle

${ }^{\wedge}$ Denotes Pearson's correlation coefficient

*Indicates significance of $<0.05$

Higher $\mathrm{Na}_{\mathrm{M}}^{+}$was also associated with low $\Phi$ at low current frequencies and capacitance (Table 2). $\mathrm{Na}_{\mathrm{SC}}^{+}$and $\mathrm{Na}_{\text {AveSC }+\mathrm{M}}^{+}$correlated negatively with impedance measurements at all frequencies (Table 3 ).

\section{Tissue FWC, its distribution and association to $\mathrm{Na}^{+}$}

Seventeen participants (4 HC, 13 CKD) completed imaging to the same area of their lower limb for estimation of the FWC in muscle and SC. FWC did not correlate with tissue resistivity indices or BIS-derived volume parameters. However, FWC in SC correlated significantly with tissue $\mathrm{Na}^{+}$concentration (Table 3, Fig. 4).

\section{The influence of tissue $\mathrm{Na}^{+}$on $\mathrm{Re}$ and ECW estimations}

The values within $2 \mathrm{SD}$ from the mean $\mathrm{Na}_{\text {AveSC}+\mathrm{M}}^{+}$concentration in healthy controls were used as the normal reference range for this analysis (15.2-27.2 $\mathrm{mmol} / \mathrm{L})$. The equivalent Re reference range (701.8-613.10hms) was derived from Eq. 2. In the CKD cohort, the maximum and minimum $\mathrm{Na}_{\text {AveSC}+\mathrm{M}}^{+}$measurements were 42.8 and $14.6 \mathrm{mmol} / \mathrm{L}$, which represented a deviation of -3.9 to $57.4 \%$ (net $60 \%$ ) from the normal reference range. Considering that $5 \%$ variation in Re could result in a $2.5 \%$ variation in ECW [24], a $20 \%$ change in Re can translate to a 1.2-2.4 L ECW discrepancy.

\section{Discussion}

To our knowledge, this is the first study in humans to investigate the relationship between tissue $\mathrm{Na}^{+}$concentration derived using MRI and body impedance. Our results indicate that $\mathrm{Na}^{+}$concentrations correlate with impedance at both low and high frequencies, and overall Re. This means that high $\mathrm{Na}^{+}$concentrations were also linked to BIS-derived ECW readings.

The observed phenomenon of Re dependence to $\mathrm{Na}^{+}$has been previously demonstrated by Rees et al. in their experimental rat model [14]. When an intravenous infusion of hypertonic saline was used to increase body $\mathrm{Na}^{+}$concentration this resulted in a disproportionate rise of BIS-estimated ECW relative to true water volume expansion measured using tracer dilution methods (4-6\% vs. $0.5 \%$ ). Similar to our findings, this was due to an increase in Re. Ri was not influenced by tissue $\mathrm{Na}^{+}$in either of the studies. This is an important limitation of BIS algorithms and could lead to inaccuracies in characterising fluid volume states for clinical management.

Overall changes to Re can lead to overestimation of ECW and Ward et al. have demonstrated that an increase in Re of $10 \%$ can lead to a $4.9 \%$ change in ECW [24]. Changes in plasma $\mathrm{Na}^{+}$concentration during haemodialysis of up to $3.5 \%$ have been linked to changes in Re of 3.2\% [25] so it is conceivable that variations in tissue $\mathrm{Na}^{+}$and osmolality can lead to ECW overestimation. Based on our findings, a $10 \%$ increase in tissue $\mathrm{Na}^{+}$concentration can lead to an overestimation of ECW by up to $1.2 \mathrm{~L}$. Re adjustment to increasing tissue resistivity would improve BIS accuracy and aid clinical decision making, with more accurate target weight prediction in dialysis [22]. 
Fig. 3 Correlation of sodium concentration to tissue impedance, extracellular and intracellular resistance. The graphs demonstrate that MR-derived sodium concentration correlates to whole body impedance at both low and high electrical current frequencies as well as extracellular resistance. *Indicates statistical significance $(p<0.05)$. Conc concentration, $\mathrm{kg}$ kilogram, $\mathrm{kHz}$ kilohertz, $L$ litre, $m m o l$ millimole, $M R$ magnetic resonance, $\mathrm{Na}^{+}$sodium, $R e$ extracellular resistance, $R i$ intracellular resistance, $Z$ impedance
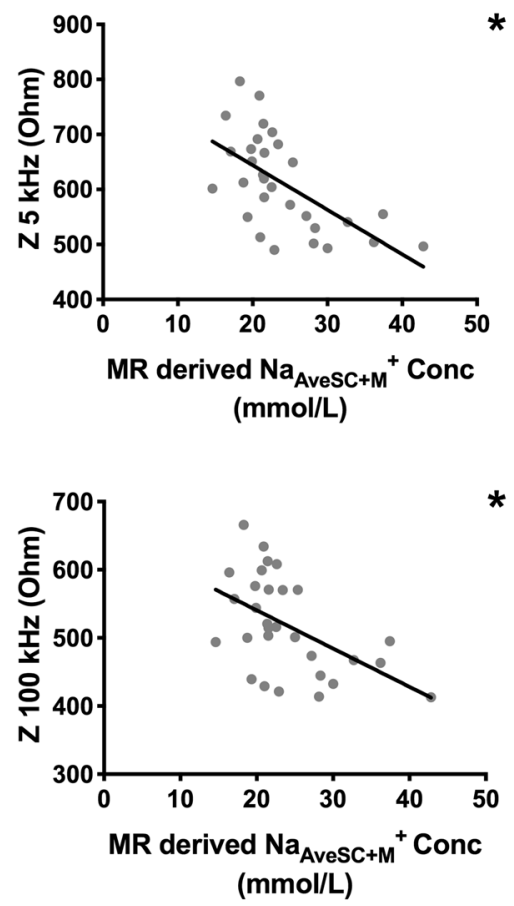
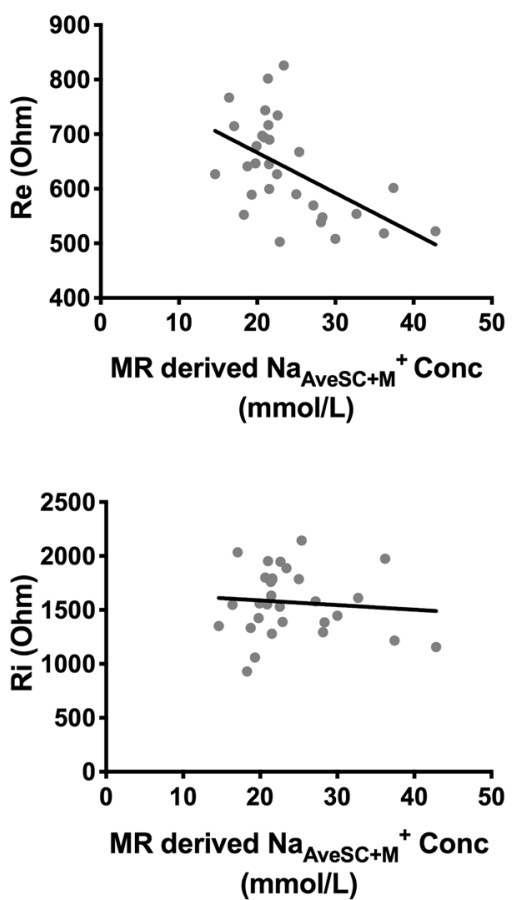

Factors that lead to the observed differences in tissue $\mathrm{Na}^{+}$ concentration are not fully understood. We attempted to examine this through MR tissue FWC assessment and examine its relationship to tissue $\mathrm{Na}^{+}$. In a series of human and animal experimental models Kopp et al. have demonstrated that tissue $\mathrm{Na}^{+}$concentration measured through ${ }^{23} \mathrm{Na} \mathrm{MRI}$, although lower than the $\mathrm{Na}^{+}$concentration of the same tissue measured through chemical analysis and ashing, exhibits a very close correlation [23]. This close association was true for both muscle and SC [23]. We demonstrated similar values of MRI-derived $\mathrm{Na}^{+}$concentration to those seen by Kopp et al. [26]. Both groups exhibited similar $\mathrm{Na}_{\mathrm{M}}^{+}$concentration but increased $\mathrm{Na}_{\mathrm{SC}}^{+}$concentration in CKD cohort. The observed differences in muscle and skin could be due to different MRI relaxation properties of the two tissues. For this reason, we also chose to analyse the tissue compartments separately in addition to the combined $\mathrm{Na}_{\mathrm{AveSC}+\mathrm{M}}^{+}$measure.

At higher frequencies, although $\mathrm{Na}_{\mathrm{SC}}^{+}$was also linked to lower impedance, $\mathrm{Na}_{\mathrm{M}}^{+}$was more closely associated with low tissue capacitance, which may indicate reduced body cellularity. The replacement of muscle mass with fat tissue and ECW is a phenomenon observed with aging and in CKD [27]. Previous studies have shown $\mathrm{Na}_{\mathrm{SC}}^{+}$accumulation independent of water accumulation [26]. Our study showed a good correlation between tissue $\mathrm{Na}^{+}$and SC FWC. Our findings do not contradict the existence of osmotically-inactive $\mathrm{Na}^{+}$but suggest that in states of deranged salt and water homeostasis the MR-imaged $\mathrm{Na}^{+}$concentration may not be entirely independent of water content. Whether part of the imaged $\mathrm{Na}^{+}$also detected the osmotically-inactive ions is unclear and cannot be determined by the techniques used in this study.

The methods used in our study provide a non-invasive approach for measuring water and $\mathrm{Na}^{+}$content, but there are certain intrinsic limitations. Our estimates of FWC are derived from MRI signals related to those obtained from pure water. While our acquisition protocol minimised the influence of other MRI parameters (chiefly relaxation times), we cannot discount the possibility that some influence from such confounders may remain. Although our study population size is comparable to similar studies using MRI for $\mathrm{Na}^{+}$imaging, the subgroup of participants that underwent measurement of FWC was relatively small and presented a limitation to our analysis. Both MRI methods used are unable to differentiate between the extracellular and intracellular compartments in the imaged tissue. In fact, MRI as well as BIS assume uniformity of extracellular to intracellular tissue across different parts of the body. This assumption has to be considered when interpreting our findings. Although BIS has been validated in a number of studies in health and CKD [9, 13, 28, 29], there are a number of limitations $[15,30]$ and one such has been demonstrated in this study. 
Fig. 4 Correlations between compartmental MR-derived sodium concentration and tissue fractional water content. Pictures A and D demonstrate that both MR-derived $\mathrm{Na}^{+}$ concentration and fractional content in the subcutaneous tissue correlate to that imaged in the muscle. Picture $\mathrm{C}$ and $\mathrm{F}$ demonstrate that subcutaneous fractional water but not muscle water content (Pictures B and E) correlate to both muscle and subcutaneous sodium concentration. *Indicates statistical significance $(\mathrm{p}<0.05)$. Conc concentration, $L$ litre, $\mathrm{mmol}$ millimole, $\mathrm{Na}^{+}$sodium
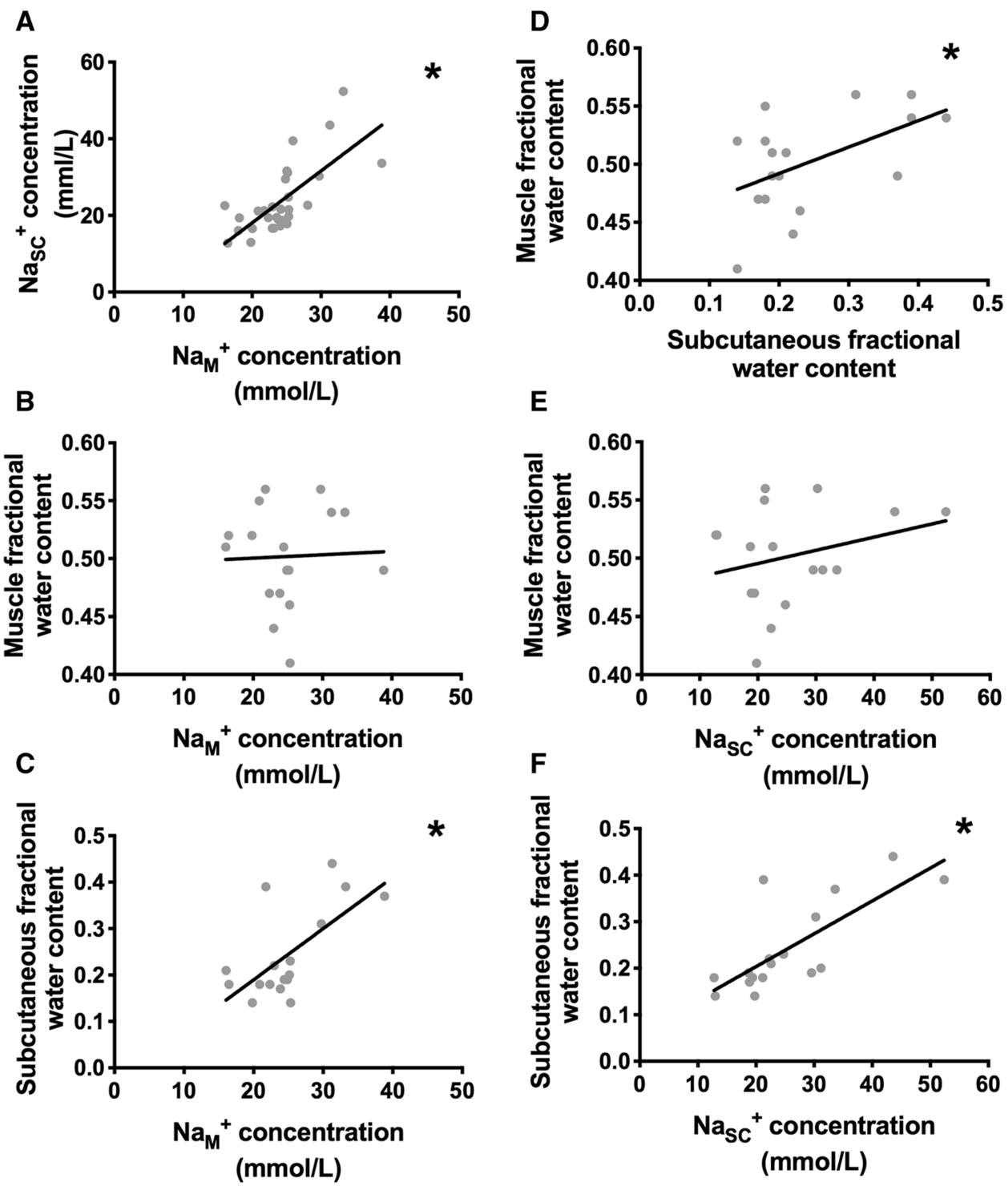

In summary, the study demonstrates an inverse and predictable relationship between $\mathrm{Re}$ and varying tissue $\mathrm{Na}^{+}$ concentration. The attributable discrepancy in Re estimations could lead to significant over- or underestimation of $\mathrm{ECW}$ volumes. Higher precision in BIS-guided fluid volume measurements could be achieved with adjustments to algorithms to account for this effect.

Acknowledgements We would like to thank the clinical and technical staff at the participating units, the Manchester Renal Research and Transplant Laboratory and the University of Manchester Imaging Facilities for their help and support. The study was funded through a charitable grant from Kidneys for Life and an internal University of Manchester Magnetic Imaging Facilities grant for proof of concept imaging studies.
Funding The research reported in this publication was supported by the Cancer Research UK and Engineering and Physical Science Research Council Cancer Image Centre in Cambridge and Manchester and the National Institute for Health Research (NIHR) Devices for Dignity Medtech Co-operative. The views expressed are those of the authors and not necessarily those of the NHS, the NIHR or the Department of Health.

\section{Compliance with ethical standards}

Ethical approval All procedures performed in studies involving human participants were in accordance with the ethical standards of the institutional and/or national research committee and with the 1964 Helsinki declaration and its later amendments or comparable ethical standards. 
Conflict of interest GJMP is a shareholder and director in Bioxydyn, a company with an interest in quantitative MRI. All other authors declare that they have no other conflict of interest.

Open Access This article is distributed under the terms of the Creative Commons Attribution 4.0 International License (http://creativeco mmons.org/licenses/by/4.0/), which permits unrestricted use, distribution, and reproduction in any medium, provided you give appropriate credit to the original author(s) and the source, provide a link to the Creative Commons license, and indicate if changes were made.

\section{References}

1. Mitsides N, Cornelis T, Broers NJH et al (2017) Extracellular overhydration linked with endothelial dysfunction in the context of inflammation in haemodialysis dependent chronic kidney disease. PLoS One. 12(8):e0183281. https://doi.org/10.1371/journ al.pone. 0183281

2. Dekker MJE, Marcelli D, Canaud BJ et al (2017) Impact of fluid status and inflammation and their interaction on survival: a study in an international hemodialysis patient cohort. Kidney Int 90(5):1214-1223

3. Tsai Y-CC, Chiu Y-WW, Tsai J-CC et al (2015) Association of fluid overload with cardiovascular morbidity and all-cause mortality in stages 4 and 5 CKD. Clin J Am Soc Nephrol. 10(1):39-46

4. Hung S-C, Kuo K-L, Peng C-H et al (2014) Volume overload correlates with cardiovascular risk factors in patients with chronic kidney disease. Kidney Int 85(3):703-709. https://doi. org/10.1038/ki.2013.336

5. Onofriescu M, Mardare NG, Segall L et al (2012) Randomized trial of bioelectrical impedance analysis versus clinical criteria for guiding ultrafiltration in hemodialysis patients: effects on blood pressure, hydration status, and arterial stiffness. Int Urol Nephrol 44(2):583-591. https://doi.org/10.1007/s11255-011-0022-y

6. Hur E, Usta M, Toz H et al (2013) Effect of fluid management guided by bioimpedance spectroscopy on cardiovascular parameters in hemodialysis patients: a randomized controlled trial. Am J Kidney Dis 61(6):957-965. https://doi.org/10.1053/j. ajkd.2012.12.017

7. Flythe JE, Kshirsagar AV, Falk RJ, Brunelli SM (2015) Associations of posthemodialysis weights above and below target weight with all-cause and cardiovascular mortality. Clin J Am Soc Nephrol 10(5):808-816. https://doi.org/10.2215/CJN.10201014

8. Thomasset A (1963) Bio-electric properties of tissues. Estimation by measurement of impedance of extracellular ionic strength and intracellular ionic strength in the clinic. Lyon médical. 209:1325-1350

9. Zhu F, Kuhlmann MK, Kaysen GA et al (2006) Segment-specific resistivity improves body fluid volume estimates from bioimpedance spectroscopy in hemodialysis patients. J Appl Physiol 100(2):717-724. https://doi.org/10.1152/japplphysiol.00669.2005

10. Dou Y, Zhu F, Kotanko P (2012) Assessment of extracellular fluid volume and fluid status in hemodialysis patients: current status and technical advances. Semin Dial 25(4):377-387

11. Malbrain MLNG, Huygh J, Dabrowski W, De Waele JJ, Staelens A, Wauters J (2014) The use of bio-electrical impedance analysis (BIA) to guide fluid management, resuscitation and deresuscitation in critically ill patients: a bench-to-bedside review. Anaesthesiol Intensive Ther. 46(5):381-391

12. Matthie JR (2005) Second generation mixture theory equation for estimating intracellular water using bioimpedance spectroscopy. J Appl Physiol Bethesda Md 1985 99(2):780-781
13. Moissl UM, Wabel P, Chamney PW et al (2006) Body fluid volume determination via body composition spectroscopy in health and disease. Physiol Meas 27(9):921-933

14. Rees AE, Ward LC, Cornish BH, Thomas BJ (1999) Sensitivity of multiple frequency bioelectrical impedance analysis to changes in ion status. Physiol Meas 20(4):333-347. https://doi. org/10.1088/0967-3334/20/4/302

15. El-Kateb S, Davenport A (2016) Changes in intracellular water following hemodialysis treatment lead to changes in estimates of lean tissue using bioimpedance spectroscopy. Nutr Clin Pract 31(3):375-377. https://doi.org/10.1177/0884533615621549

16. Rakova N, Jüttner K, Dahlmann A et al (2013) Long-term space flight simulation reveals infradian rhythmicity in human $\mathrm{Na}(+)$ balance. Cell Metab 17(1):125-131. https://doi.org/10.1016/j. cmet.2012.11.013

17. Charra B, Chazot C, Jean $\mathrm{G}$ et al (2004) Role of sodium in dialysis. Minerva Urol Nefrol 56(3):205-213

18. Titze J, Dahlmann A, Lerchl K et al (2013) Spooky sodium balance. Kidney Int. 85:1-9

19. Titze J, Shakibaei M, Schafflhuber M et al (2004) Glycosaminoglycan polymerization may enable osmotically inactive $\mathrm{Na}^{+}$storage in the skin. Am J Physiol Heart Circ Physiol. 287(1):H203-H208

20. Mchugh DJ, Riemer F, Haroon HA, Parker GJM, Gallagher FA. Standardisation and quantification of 23Na-MRI: repeatability and reproducibility of sodium imaging across two independent sites. In: In Proc. Intl. Soc. Mag. Reson. Med. Singapore; 2016;24, 3978

21. Dahlmann A, Dörfelt K, Eicher F et al (2014) Magnetic resonance-determined sodium removal from tissue stores in hemodialysis patients. Kidney Int. https://doi.org/10.1038/ki.2014.269

22. Davies SJ, Davenport A (2014) The role of bioimpedance and biomarkers in helping to aid clinical decision-making of volume assessments in dialysis patients. Kidney Int 86(3):489-496

23. Kopp C, Linz P, Wachsmuth L et al (2012) (23)Na magnetic resonance imaging of tissue sodium. Hypertension 59(1):167-172

24. Ward LC, Elia M, Cornish BH (1998) Potential errors in the application of mixture theory to multifrequency bioelectrical impedance analysis. Physiol Meas 19(1):53-60. https://doi. org/10.1088/0967-3334/19/1/005

25. Scharfetter H, Wirnsberger GH, Holzer H, Hutten H (1997) Influence of ionic shifts during dialysis on volume estimations with multifrequency impedance analysis. Med Biol Eng Comput. 35(2):96-102

26. Kopp C, Linz P, Dahlmann A et al (2013) 23Na magnetic resonance imaging-determined tissue sodium in healthy subjects and hypertensive patients. Hypertension 61(3):635-640

27. Bellizzi V (2006) Early changes in bioelectrical estimates of body composition in chronic kidney disease. J Am Soc Nephrol 17(5):1481-1487. https://doi.org/10.1681/ASN.2005070756

28. Chamney PW, Wabel P, Moissl UM et al (2007) A whole-body model to distinguish excess fluid from the hydration of major body tissues. Am J Clin Nutr 85(1):80-89

29. Kraemer M, Rode C, Wizemann V (2006) Detection limit of methods to assess fluid status changes in dialysis patients. Kidney Int 69(9):1609-1620. https://doi.org/10.1038/sj.ki.5000286

30. Carter M, Morris AT, Zhu F et al (2005) Effect of body mass index (BMI) on estimation of extracellular volume (ECV) in hemodialysis (HD) patients using segmental and whole body bioimpedance analysis. Physiol Meas 26(2):S93-S99. https://doi. org/10.1088/0967-3334/26/2/009

Publisher's Note Springer Nature remains neutral with regard to jurisdictional claims in published maps and institutional affiliations. 